Revue des patrimoines

\title{
Le Millenáris à Budapest, la reconversion de l'ancienne usine de construction électrique Ganz
}

\section{Györgyi Németh}

\section{(2) OpenEdition}

\section{Journals}

Édition électronique

URL : http://journals.openedition.org/insitu/11803

DOI : $10.4000 /$ insitu. 11803

ISSN : 1630-7305

Éditeur

Ministère de la Culture

Référence électronique

Györgyi Németh, «Le Millenáris à Budapest, la reconversion de l'ancienne usine de construction électrique Ganz », In Situ [En ligne], 26 | 2015, mis en ligne le 08 juillet 2015, consulté le 27 mars 2020. URL : http://journals.openedition.org/insitu/11803 ; DOI : https://doi.org/10.4000/insitu.11803

Ce document a été généré automatiquement le 27 mars 2020

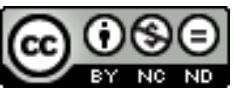

In Situ Revues des patrimoines est mis à disposition selon les termes de la licence Creative Commons Attribution - Pas d'Utilisation Commerciale - Pas de Modification 4.0 International. 


\title{
Le Millenáris à Budapest, la reconversion de l'ancienne usine de construction électrique Ganz
}

\author{
Györgyi Németh
}

1 Le Millenáris, un centre d'expositions et de programmes culturels, a été créé à Budapest afin d'accueillir une exposition sur la science et la technologie, pour célébrer le millénaire de la création d'un État hongrois dans le bassin des Carpates. Sous le titre «Dreamers of Dreams: Hungarians of Worldwide Significance » (les rêveurs de rêves, figures hongroises d'importance mondiale), cette exposition a ouvert ses portes en 2001 dans un groupe de bâtiments réutilisés faisant partie du site de l'ancienne usine de construction électrique Ganz. Ce projet de régénération urbaine est le premier en Hongrie à englober l'ensemble d'un grand complexe industriel. Il a eu des retombées positives très importantes pour le public et sert de modèle pour d'autres projets similaires à travers tout le pays.

\section{Histoire de l'usine de construction électrique Ganz}

2 L'usine Ganz était une grande usine hongroise célèbre dans le monde entier. Elle a pour origine une usine métallurgique, une fonderie de fer, créée en 1845 par Ábrahám Ganz. Né en Suisse, cet entrepreneur arrive en Hongrie après avoir acquis au préalable une expérience professionnelle en Alsace et à Paris sur les derniers procédés de fonte de fer. Grâce à ses compétences professionnelles, et grâce aussi à sa créativité, la fonderie connut un grand succès comme entreprise. Elle fut la première en Europe à utiliser le procédé de refroidissement direct pour la fabrication de roues de chemin de fer. Plus tard, Ganz améliora encore cette technologie par l'introduction d'antimoine, et ce ne fut là qu'une de ses nombreuses innovations. Avant sa mort, en 1867, les produits brevetés de son usine furent récompensés par des médailles de bronze à deux expositions industrielles à Paris, ainsi qu'à l'Exposition universelle de Londres; il emporta aussi une médaille d'argent à une exposition industrielle suisse ${ }^{1}$. 
3 Après le décès de Ganz, l'usine poursuivit son expansion pour devenir une entreprise majeure sous la direction d'András Mechwart. La stratégie de développement de celuici visait la satisfaction de besoins économiques sur le marché domestique ainsi qu’à l'étranger. Il fabriquait des machines de technologie tout à fait récente, comme par exemple les turbines Francis, ou des trains de laminoir de sa propre conception, utilisant des cylindres refroidis à rainurages. Lors de l'Exposition universelle de Paris, en 1878 , il se rendit compte du potentiel du marché pour la production d'appareils électriques. Il établit un département électrotechnique qui connut un développement spectaculaire $^{2}$. En 1886, trois jeunes ingénieurs de la firme, Károly Zipernowsky, Miksa Déri et Ottó Titusz Bláthy, prirent un brevet pour un système de transport d'énergie électrique sur de longues distances avec un courant alternatif de haut voltage fondé sur la connexion en parallèle de transformateurs fermés à noyau de fer. Grâce à ce brevet, l'entreprise reçut de nombreuses commandes d'installation de centrales et réseaux électriques dans différents pays d'Europe. La centrale de Cerchi, avec ses générateurs à vapeur, ainsi que la centrale hydroélectrique de Tivoli, fournissant toutes les deux de l'électricité pour le réseau urbain à Rome, furent remarquées pour leur niveau d'excellence et leur technologie innovante ${ }^{3}$.

4 L'usine hongroise développa aussi des systèmes triphasés de traction ferroviaire, suivant les conceptions de Kálmán Kandó, qui, lors d'un séjour en tant que jeune ingénieur à la Compagnie Fives-Lille de Paris, avait remarqué les capacités de traction du moteur à induction de Nikola Tesla ${ }^{4}$. Mobilisant sa grande ingéniosité dans la conception de technologies infrastructurelles, Kandó prit la direction de l'installation de la première grande ligne ferroviaire en Europe à être électrifiée, la ligne de Valtellina en Italie, utilisant les appareils de son invention fabriqués à l'usine Ganz ${ }^{5}$. En 1897, afin de pouvoir répondre à la demande croissante en matière d'équipements et d'appareils électriques, une nouvelle usine fut construite, appelée par la suite usine de construction électrique Ganz ${ }^{6}$ (fig. 1). 
Figure 1

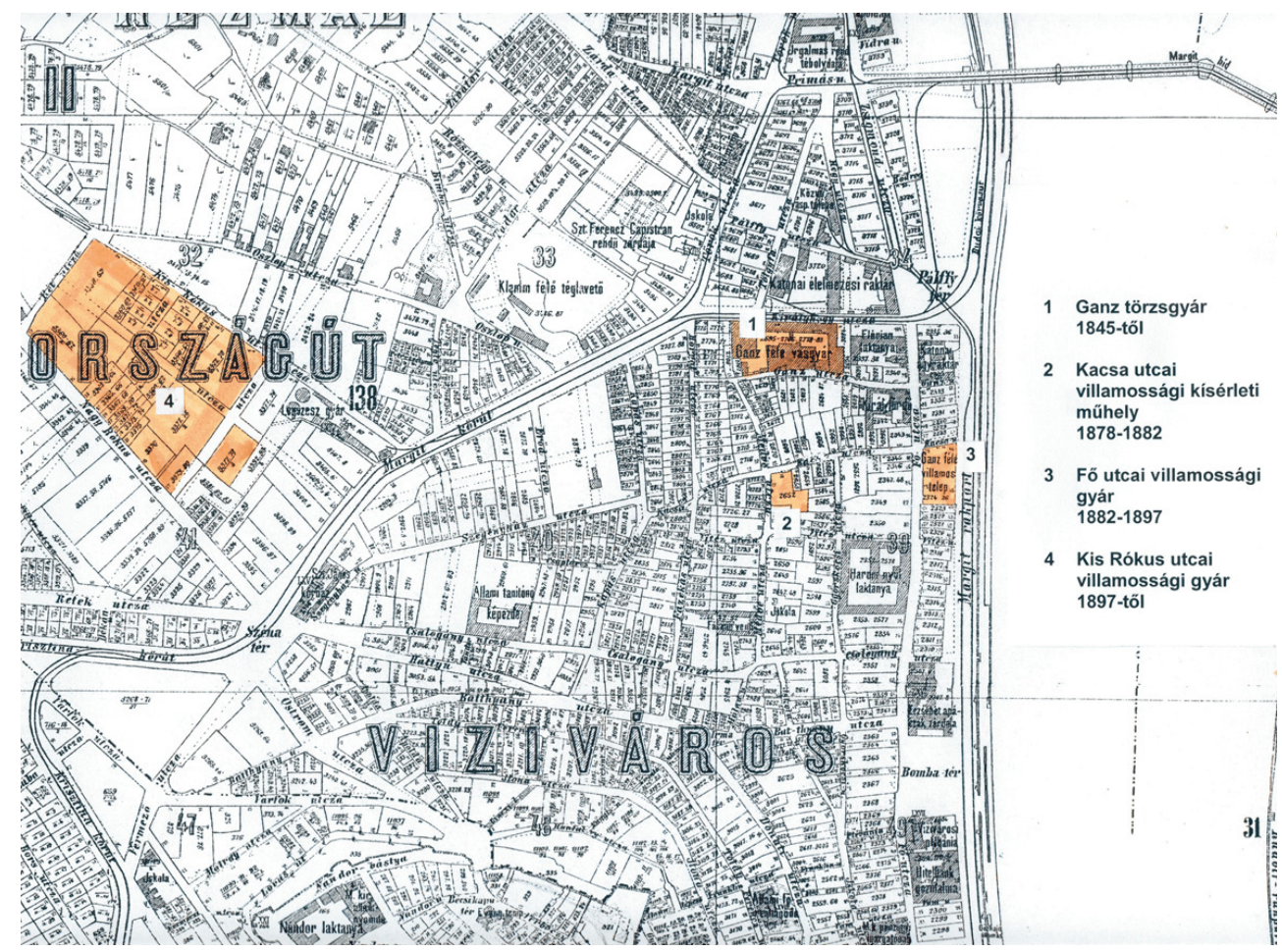

Détail d'une carte de Budapest datant de 1896, conservée aux archives de la Ville et montrant la fonderie de fer établie par Abraham Ganz en 1845 ainsi que les différents éléments de l'usine d'électricité : 1) fonderie de fer (1845-1964) ; 2) département électrotechnique (1878-1882) ; 3) usine électrique (1882-1897) ; 4) Ganz usine électrique (1897-2000). Repro. BAZSÓ, Gábor, op.cit., voir note 8.

Repro. Németh, Györgyi. @ G Györgyi Németh.

L'accroissement des capacités productives amena un développement significatif du site au début des années 1910 (fig. 2) et de nouveau dans les années 1940 et $1960^{7}$. Mais un développement technologique insuffisant et une gestion inefficace sous le régime communiste, associés ensuite aux conditions défavorables du marché dans les années 1980, amenèrent l'entreprise à la privatisation en 1991 et à sa fusion avec des entreprises étrangères, pour éviter une mise en liquidation. L'entreprise fait partie aujourd'hui du groupe indien Crompton Greaves. La production s'est délocalisée vers d'autres sites en Hongrie avec l'abandon des terrains d'origine, propriété de l'État, à la fin des années $1990^{\circ}$. 


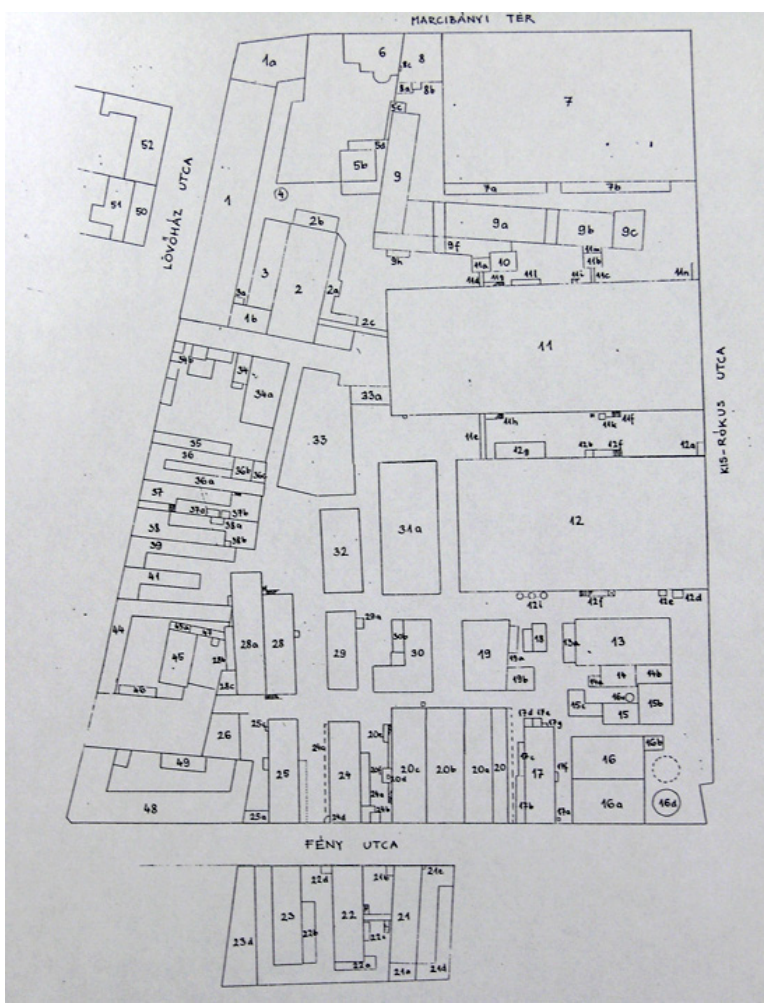

Plan de l'usine de construction électrique Ganz, à la suite de la réalisation des projets de construction des années 1910. Voir note 7.

Repro. Németh, Györgyi. @ G Györgyi Németh.

\section{Le projet de régénération et ses retombées positives}

\section{L'architecture industrielle : valeurs conservées, valeurs ajoutées}

6 La conservation de l'usine Ganz, par le biais d'un projet de régénération urbaine, s'est avérée une excellente initiative à plusieurs égards. Les responsables du projet ont réussi à préserver l'atmosphère du paysage industriel ainsi que les qualités architecturales de ses bâtiments de production tout en sauvegardant la mémoire d'une importante entreprise hongroise. Grâce à ce projet, le Millenáris occupe dorénavant presque les deux tiers du site du complexe industriel, en préservant les principales caractéristiques de son plan d'origine. Quelques structures et quelques ateliers sans grande valeur architecturale, ainsi que des édifices à étages datant de la deuxième moitié du $\mathrm{xx}^{\mathrm{e}}$ siècle, ont été démolis immédiatement après la fermeture du site, mais les quatre grandes halles et le principal bâtiment administratif, antérieurs à la Première Guerre mondiale, ont été préservés ${ }^{9}$ (fig. 3). 
Figure 3

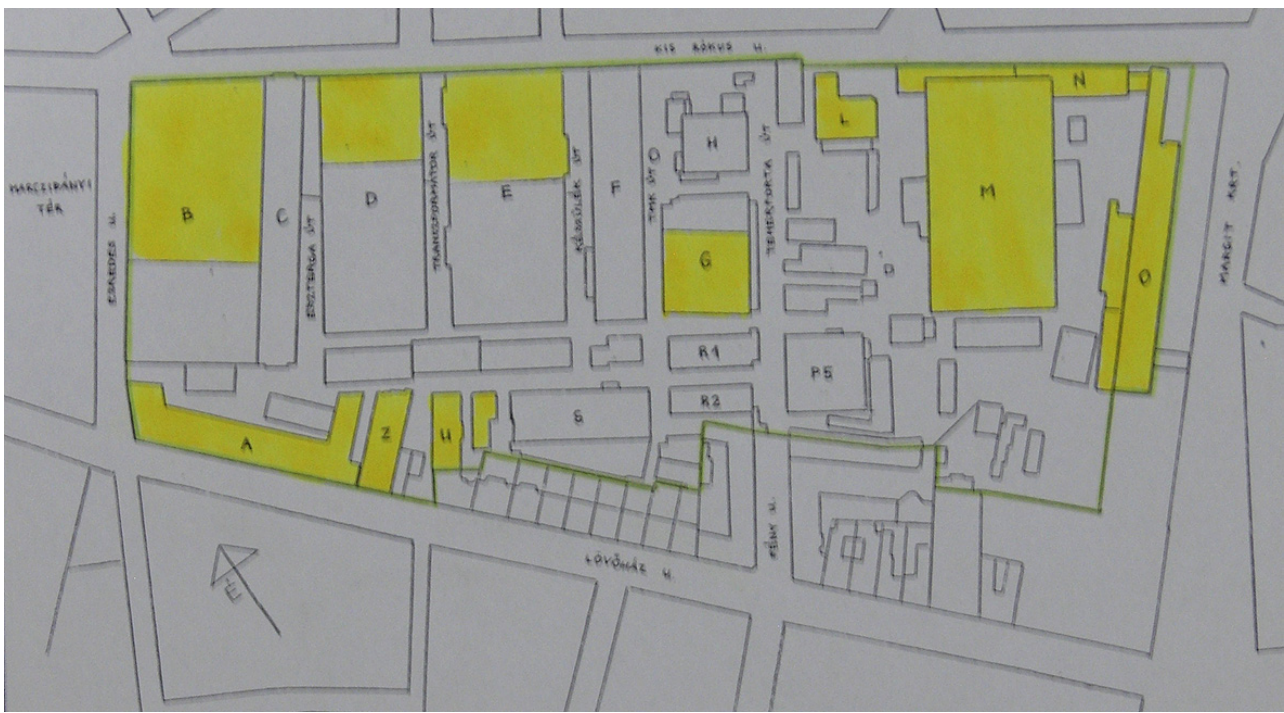

Plan du site de l'usine de construction électrique en 1996 : les bâtiments indiqués en jaune, à savoir le bâtiment des bureaux (A), la halle de montage (B), la halle d'usinage (D), I'usine à transformateurs (E) et l'atelier de réparations $(G)$ sont totalement ou partiellement préservés. Les autres ont été démolis. Les bâtiments $L, M, N$ et $\mathrm{O}$, en dehors du périmètre du site du Millenáris, n'ont pas encore été reconvertis. Voir note 7

Repro. Németh, Györgyi. @ Györgyi Németh.

Les bâtiments les plus anciens du site sont la halle d'usinage et le bâtiment de l'administration, construits en 1897, suivis par la halle de montage de 1912. Placée parallèlement à la halle d'usinage, l'usine à transformateurs datait de l'origine, 1897 (fig. 4), mais l'édifice qui subsiste est une construction plus récente, de 1947, le bâtiment d'origine ayant été endommagé par des bombardements pendant la Deuxième Guerre mondiale. Quant à l'atelier de réparation des machines, il date peut-être de 1897, du moins en partie; le bâtiment dans son ensemble a été achevé vers 1912 ou au cours des années $1930^{10}$. 


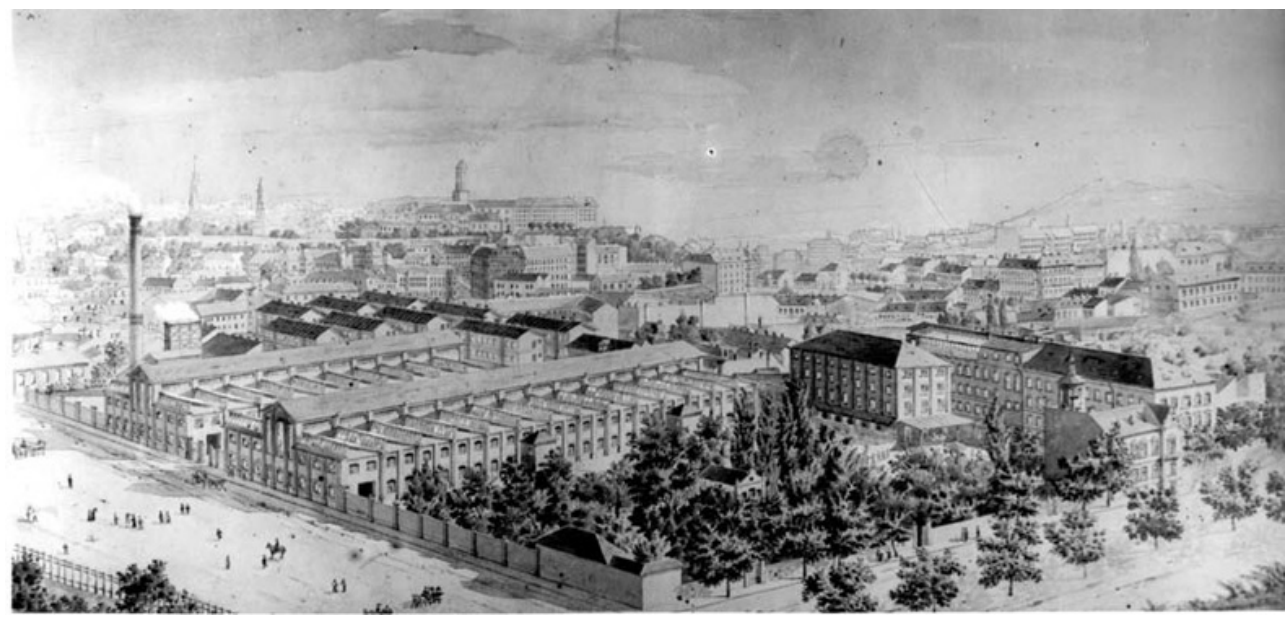

Gravure datant de la fin du $x x^{\mathrm{e}}$ siècle montrant le bâtiment des bureaux ainsi que la halle d'usinage et I'usine à transformateurs. La halle de montage a été construite ultérieurement à l'angle du site, encore recouvert d'arbres sur cette image. SZEKERES, József et TÓTH, Árpád. A Klement Gottwald (Ganz) Villamossági Gyár története [Histoire de l'usine de construction électrique Klement Gottwald (Ganz)]. Budapest : Közgazdasági és Jogi Kiadó, 1962, p. 91.

Repro. Németh, Györgyi. (c) Györgyi Németh.

Les travaux de reconstruction entrepris en 2001 se sont focalisés sur les bâtiments d'ateliers qui étaient dans un état assez dégradé. Le bâtiment administratif, encore dans un état relativement correct, ne fit pas l'objet de travaux à cette époque. L'équipe chargée du projet s'est mise d'accord sur le principe de conserver dans leur état historique les façades donnant vers l'extérieur du site, sur les rues environnantes (fig. 5, fig. 6), tandis que l'apparence des bâtiments à l'intérieur du site pouvait évoluer.

Figure 5

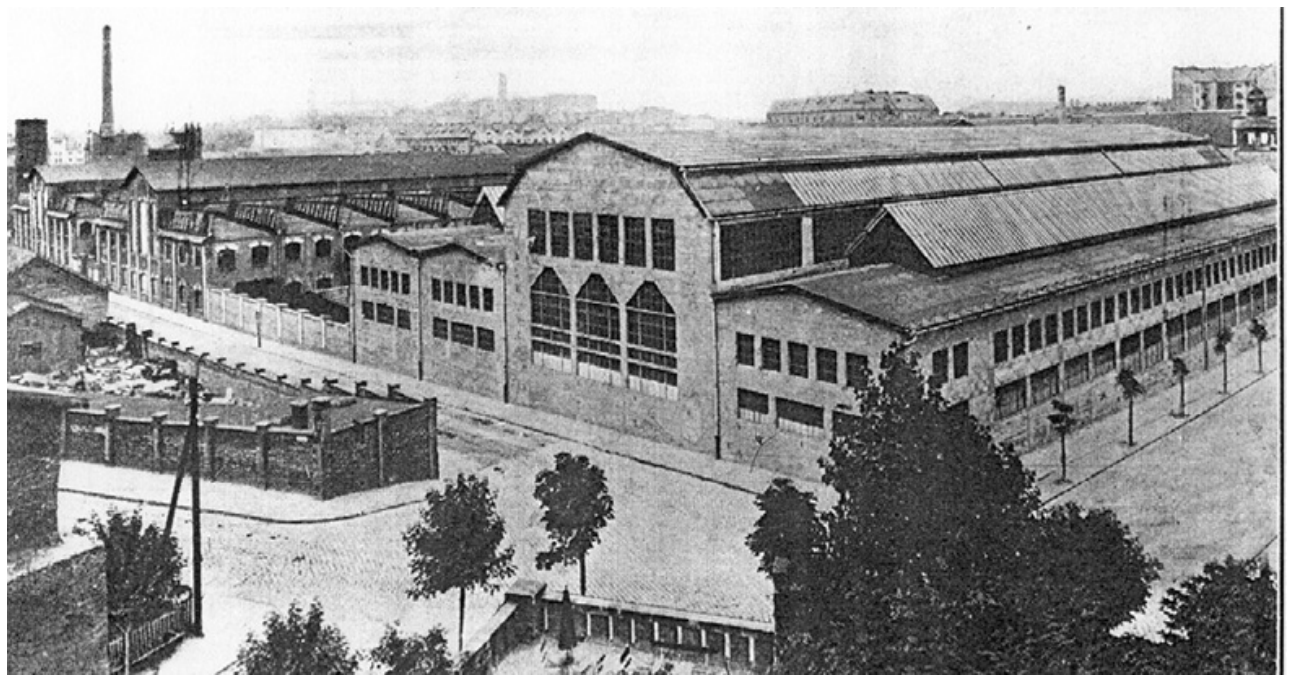

La façade sur rue de la halle de montage sur une photographie de 1925. A villamos transzformátor negyvenéves története : 1885-1925 [Les quarante années d'histoire de l'usine à transformateurs, 1885-1925]. Budapest : [Ganz], 1925, p. 38.

Repro. Németh, Györgyi. (c) Györgyi Németh. 
Figure 6

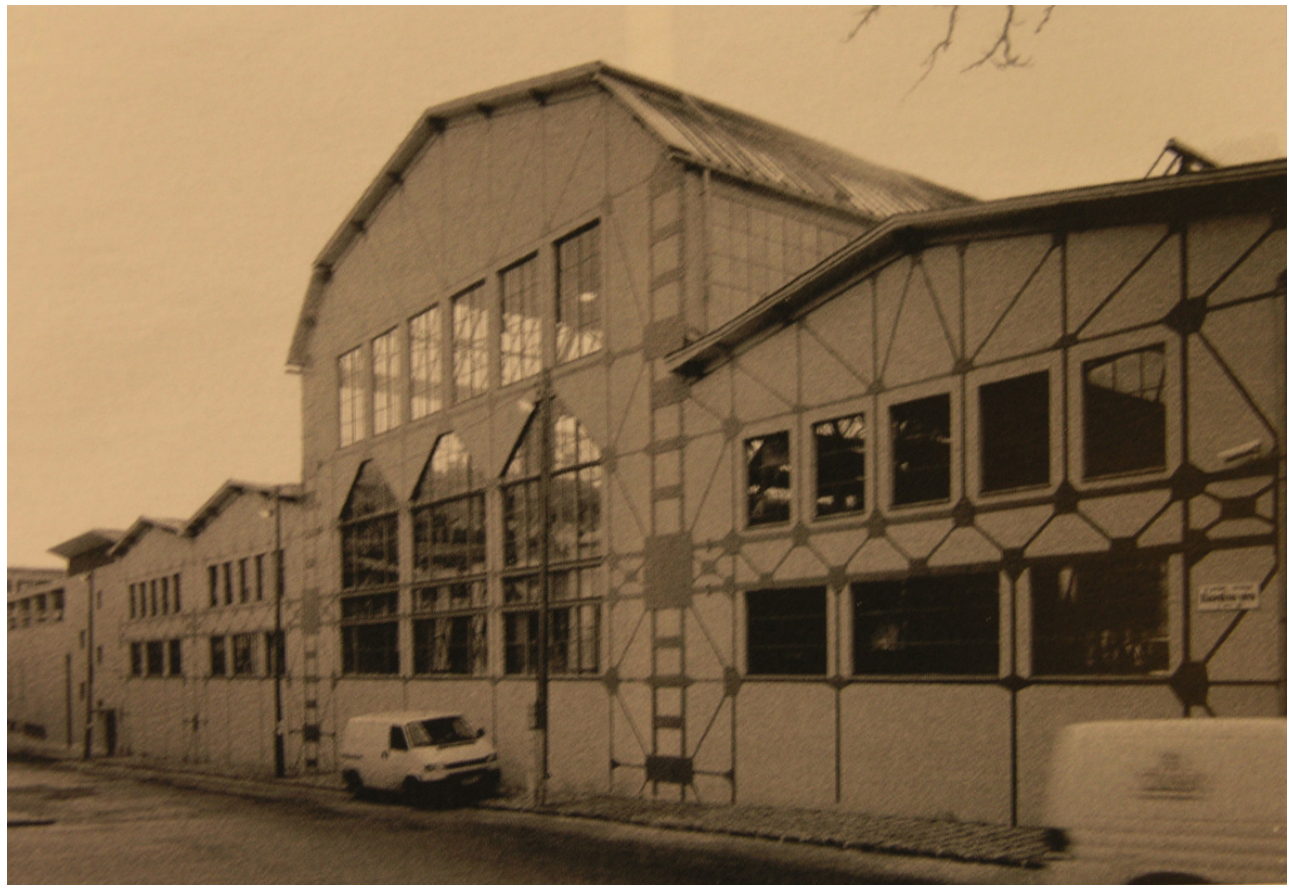

L'aspect contemporain de la façade sur rue de la halle de montage. RÉPAY, András. «Millenium Exhibition and Program Center 2nd District, Budapest». Dans KIRIZSÁN, Imola et HLAVATHY, Izabella (eds). A realistic approach to built heritage conservation. Baia Mare, 25th-28th May, 2005. Conference series on theoretical and practical issues of built heritage conservation. Cluj : Utilitas, 2005, p. 161.

Repro. Németh, Györgyi. @ Györgyi Németh.

9 Ceci dit, en dépit de quelques démolitions partielles et des contraintes pratiques de réutilisation des bâtiments, le caractère industriel est encore sensible dans les ateliers reconvertis à de nouveaux usages. La nouvelle façade vitrée de la halle d'usinage, par exemple (fig. 7), préserve la section de cette halle industrielle dans son élévation basilicale, tandis que le théâtre en plein air créé devant l'usine à transformateurs utilise la charpente et la toiture d'origine du bâtiment, raccourci (fig. 8). 
Figure 7

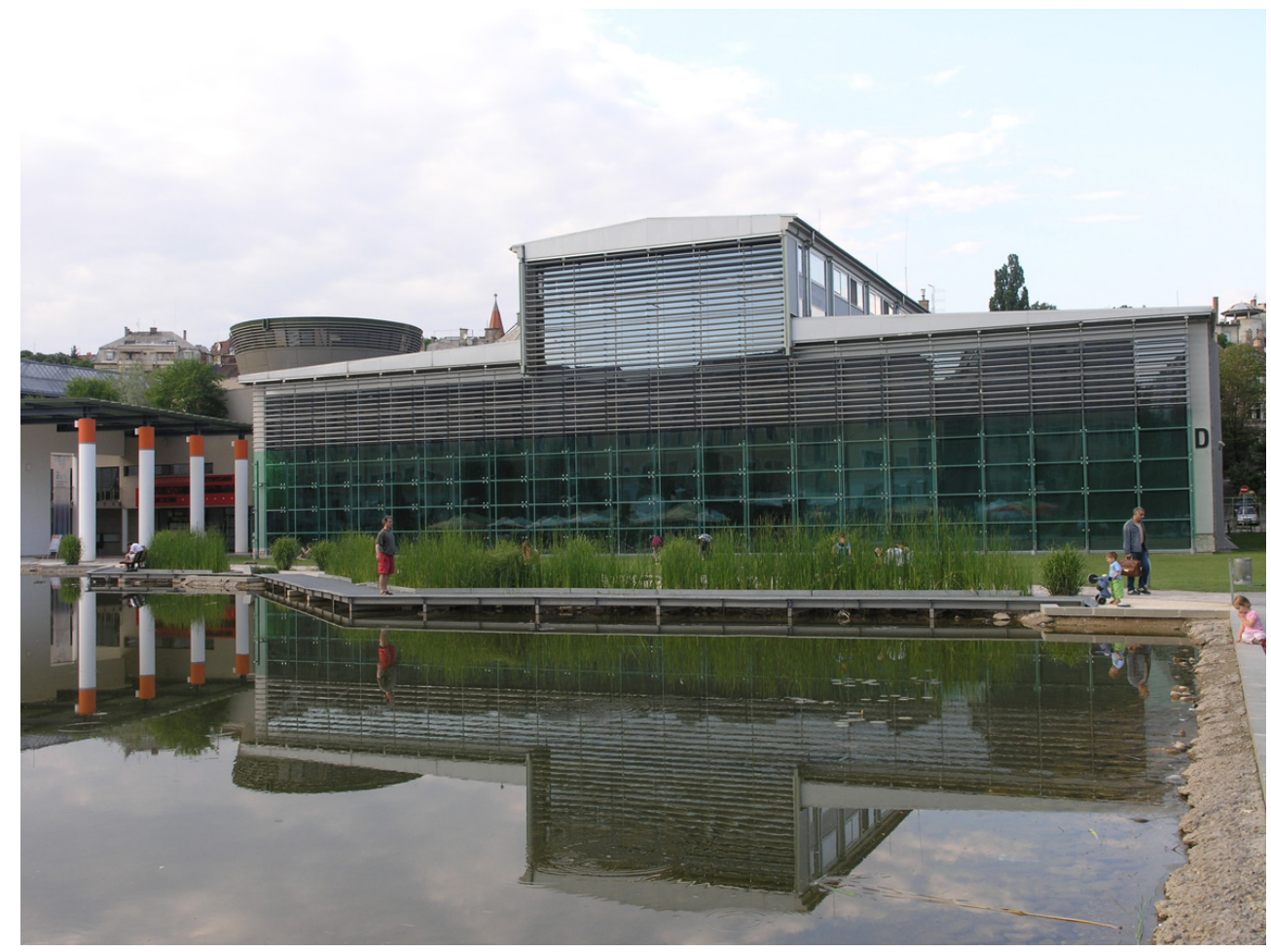

La nouvelle façade en verre de la halle d'usinage.

Phot. Németh, Györgyi. (c) Györgyi Németh. 
Figure 8

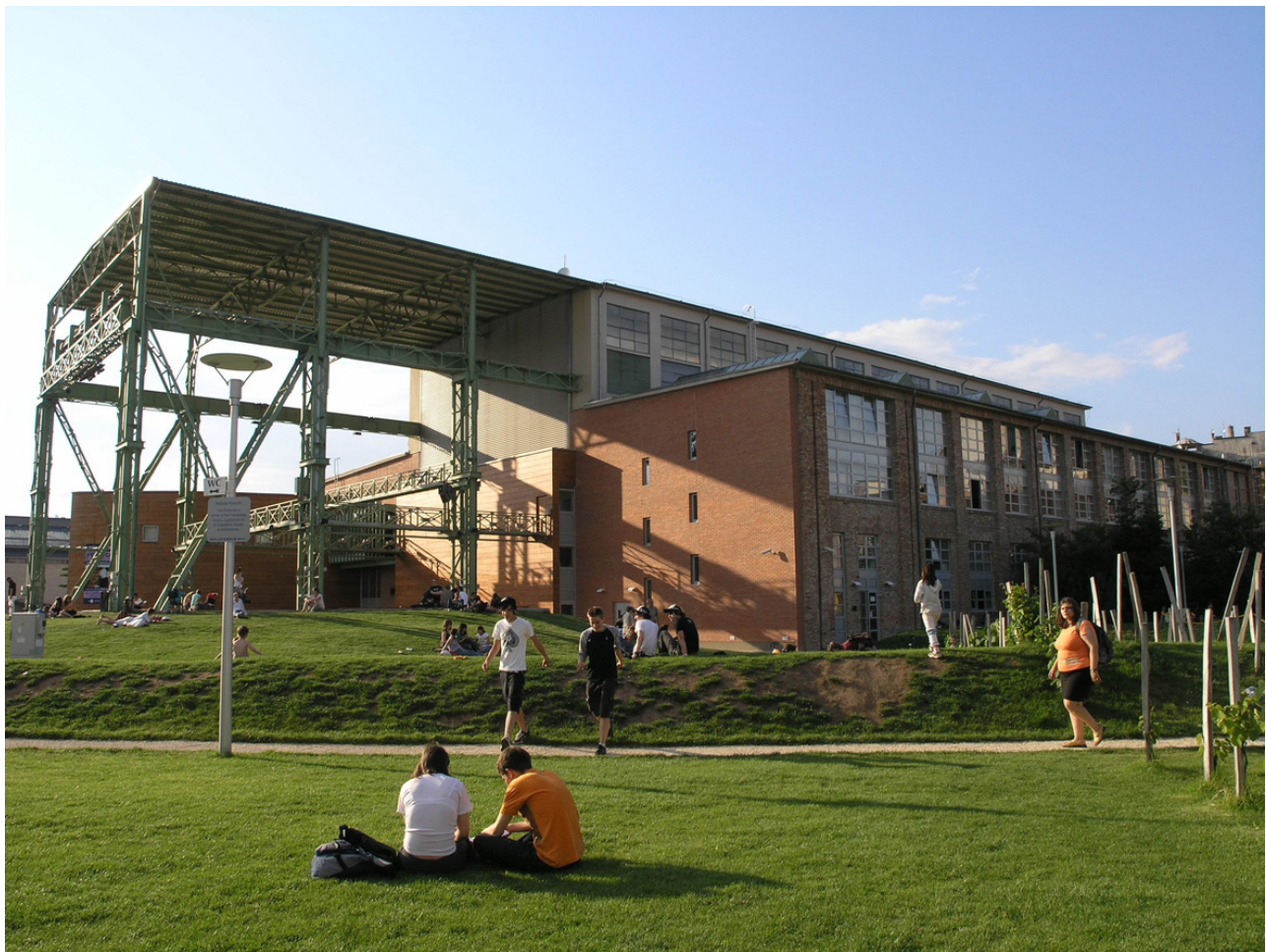

Le théâtre à ciel ouvert, créé devant l'ancienne usine à transformateurs et utilisant la charpente structurelle et couverture de l'atelier tronqué dans sa longueur.

Phot. Németh, Györgyi. (c) Németh, Györgyi.

L'acier et la brique, matériaux caractéristiques de l'architecture industrielle à l'époque de la construction de l'ensemble, ont été utilisés pour la construction d'une façade contemporaine pour la halle de montage (fig. 9) et pour un escalier supplémentaire et une terrasse extérieure pour l'atelier de réparation, préservant ainsi l'image historique de son extérieur (fig. 10). 
Figure 9

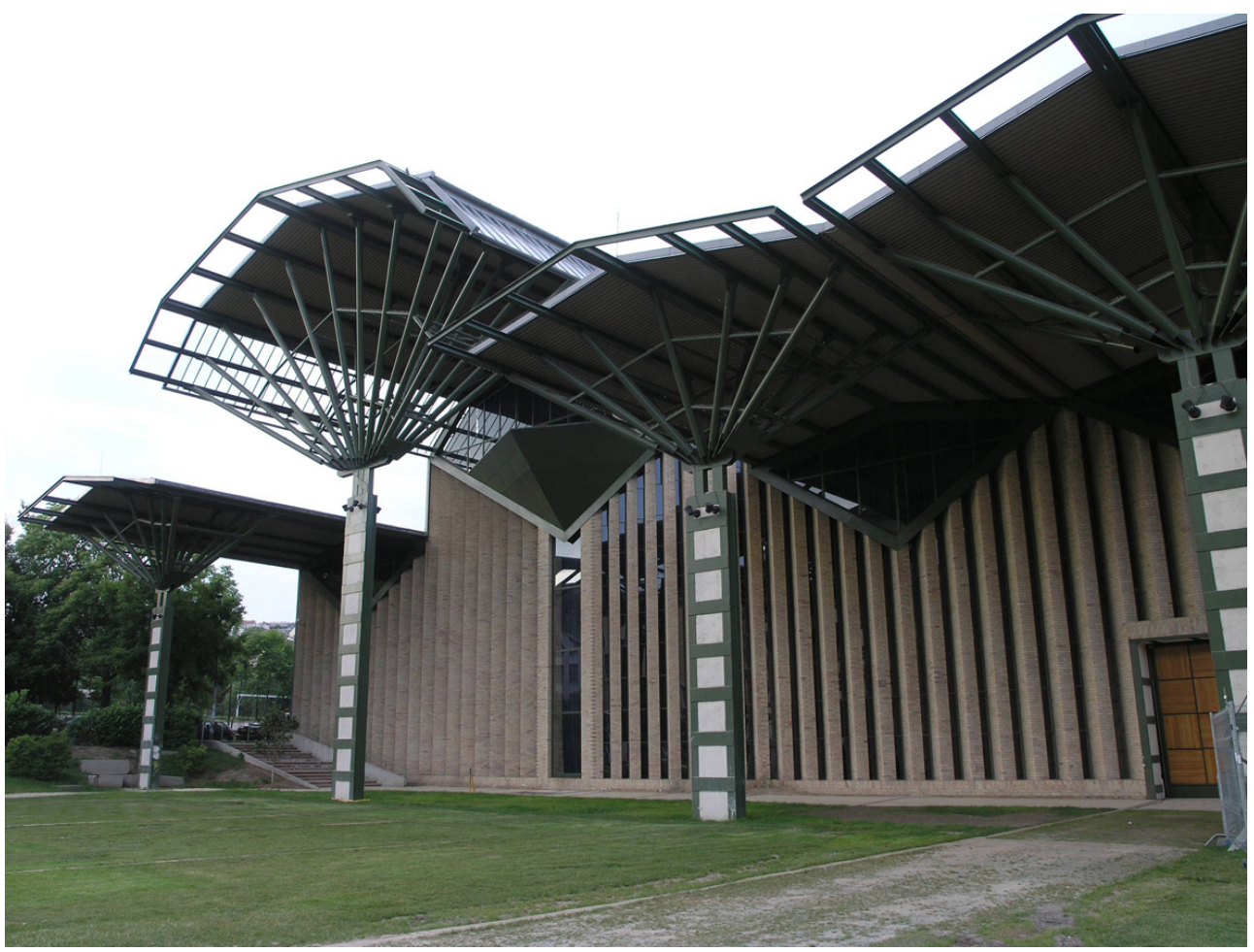

La façade contemporaine en brique de la halle de montage.

Phot. Németh, Györgyi. (c) Györgyi Németh.

Figure 10

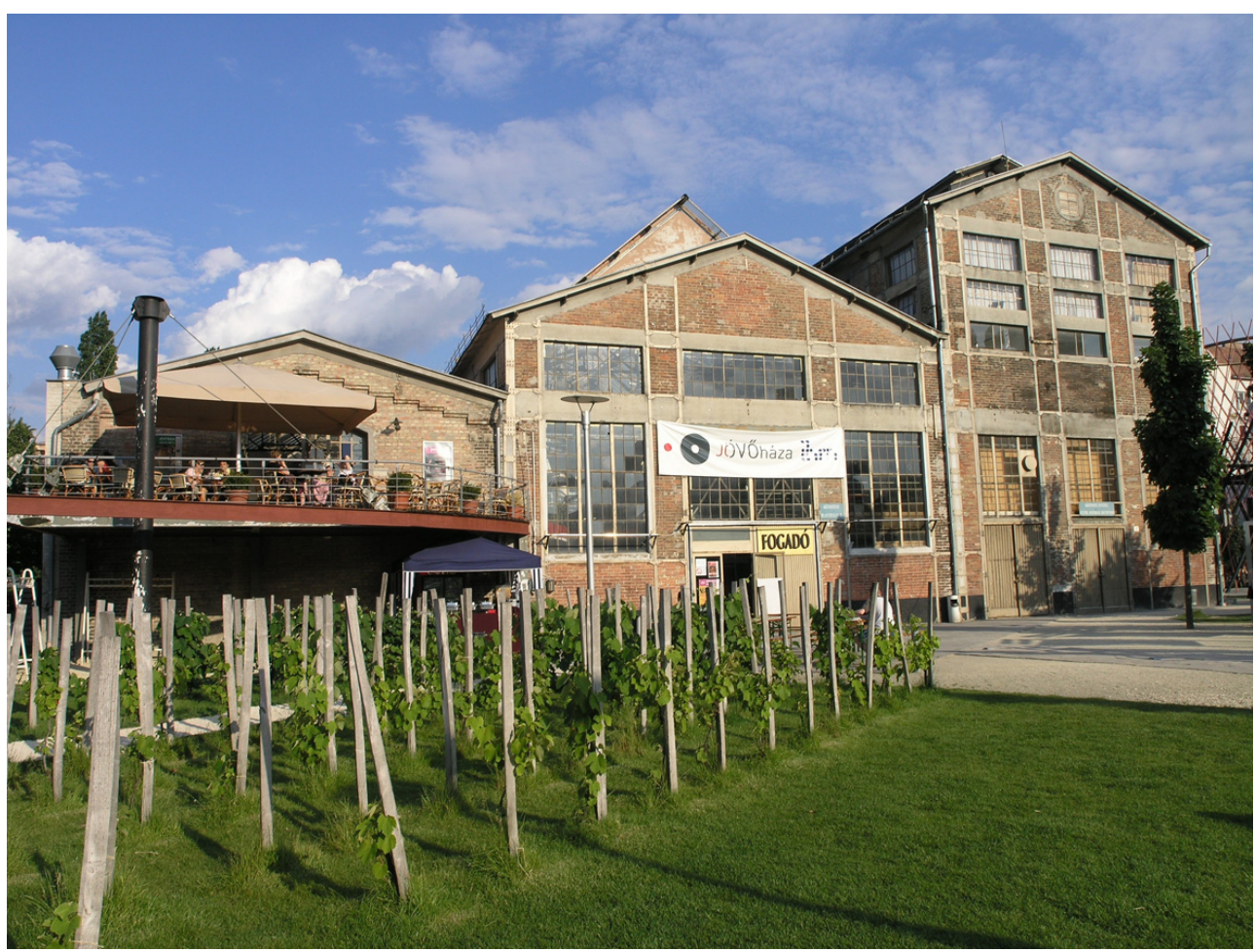

L'atelier de réparations avec sa terrasse extérieure.

Phot. Németh, Györgyi. (c) Györgyi Németh. 
11 L'équipe de conception a eu ce même souci d'authenticité pour l'aménagement intérieur des bâtiments. Les charpentes en fer d'origine ont été conservées partout où c'était possible, les additions contemporaines se distinguant par une couleur différente. De manière remarquable, les structures métalliques d'origine ont pu être conservées dans la halle de montage, en dépit des déformations laissées par les atteintes de la Deuxième Guerre. L'atmosphère industrielle est encore renforcée par la conservation d'une grue, encore en état de fonctionnement, et par des pavés de bois imitant ceux du plancher d'origine ${ }^{11}$.

Figure 11

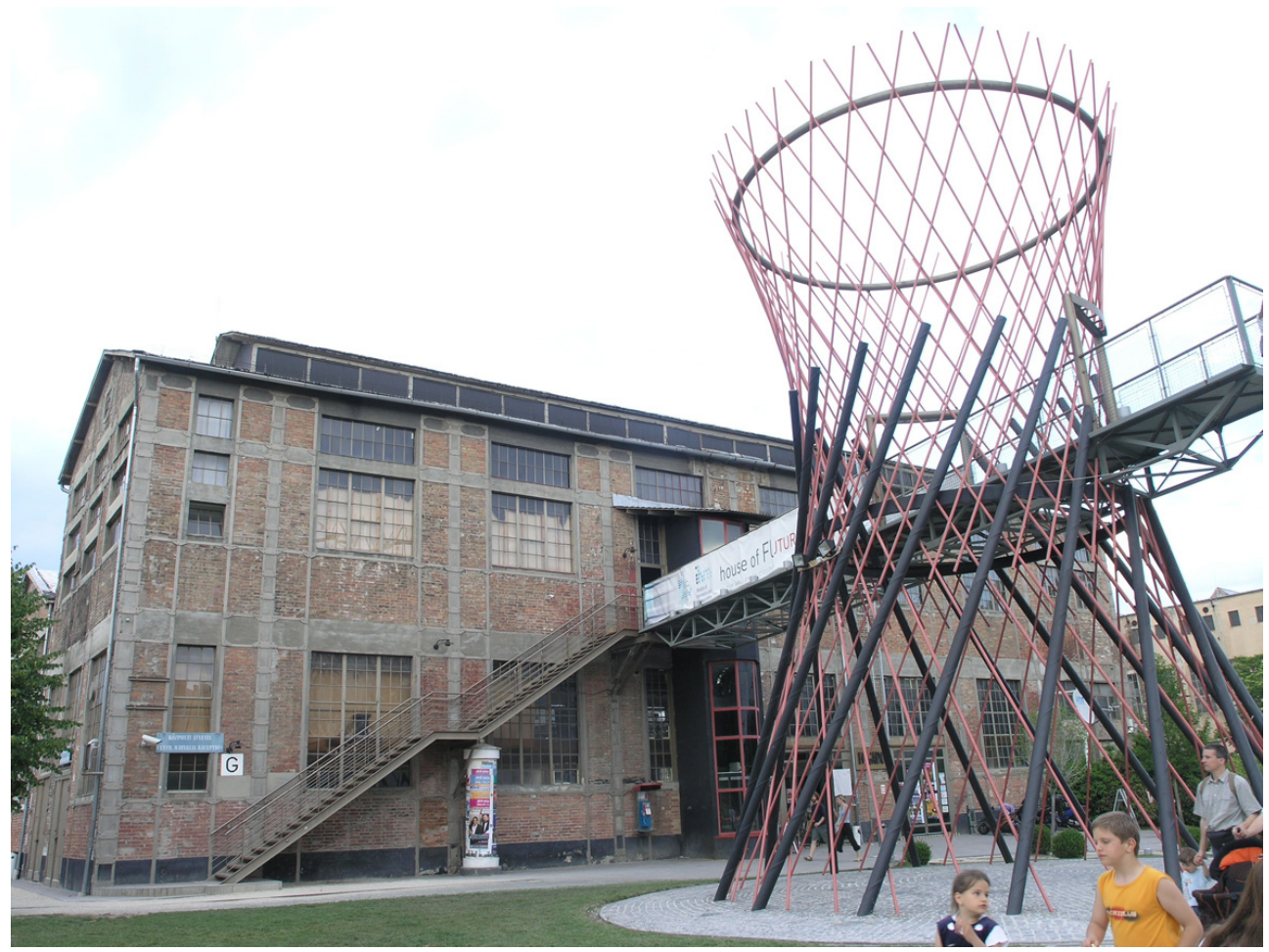

L'atelier de réparations, avec la structure sculpturale, évocatrice des tours de refroidissement inventées par Heller.

Phot. Németh, Györgyi. @ Györgyi Németh.

Outre la restauration attentive des bâtiments historiques, de nouveaux bâtiments et des œuvres d'art, conçus pour enrichir son atmosphère industrielle, ont été introduits sur le site. Tout à côté de l'entrée, une structure sculpturale (fig. 11) rappelle la forme des tours de refroidissement à condensation d'air inventées par László Heller pour les centrales actives dans des régions où l'approvisionnement en eau n'était pas fiable ${ }^{12}$. Pour la ventilation du garage souterrain, on a utilisé des cylindres en acier Corten, d'apparence rouillée, œuvre qu'on a baptisée les "pipes » de Ganz, en raison des sons émis par le passage de l'air ${ }^{13}$. Même la halle de réception et du vestibule, construite pour relier la halle d'usinage à la halle de montage et pour créer un espace d'exposition unifié, donne l'impression d'avoir été conçue pour une fonction industrielle. L'un des grands défis du projet était l'intégration d'un étang prenant place au milieu du territoire usinier pour combler le trou laissé par l'enlèvement des terres polluées. La construction au-dessus de l'eau d'un pavillon de musique, ressemblant à une structure 
industrielle ${ }^{14}$, ainsi que la création sur les bords de l'eau de passerelles caractéristiques d'usages industriels, ont contribué au succès (fig. 12).

Figure 12

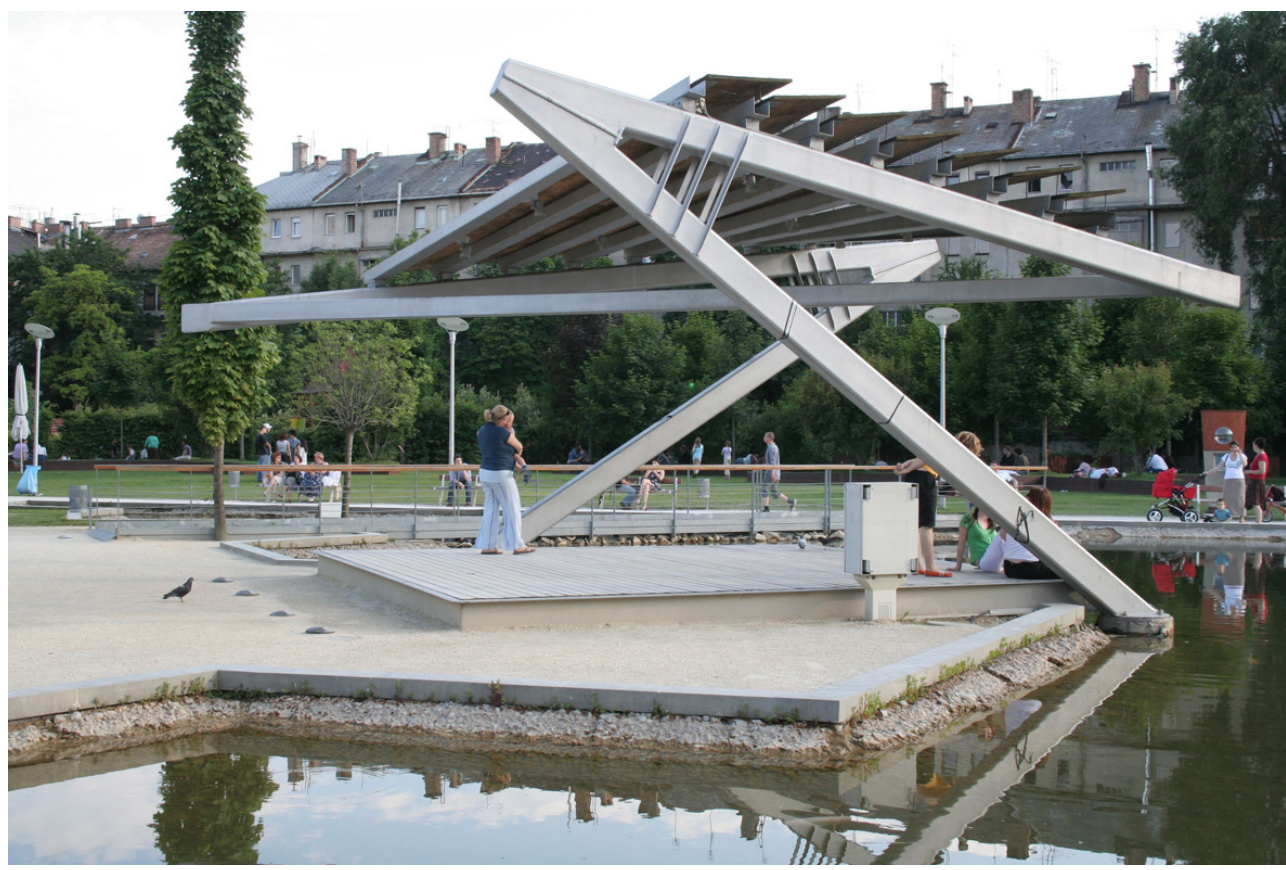

Le pavillon à musique auprès du lac.

Phot. Sandulescu, Lucian Fulger. (c) Lucian Fulger Sandulescu.

Respectant de manière rigoureuse le projet de régénération dans son ensemble, l'image contemporaine du site est celle d'un ensemble usinier datant de la fin du XIX ${ }^{e}$ siècle et du début $\mathrm{du} \mathrm{xx}^{\mathrm{e}}$, amélioré par l'intégration d'éléments de design architectural récents. Grâce aux différentes valeurs incarnées dans cette reconversion de grande qualité, le Millenáris a été très apprécié sur les plans nationaux et internationaux. En 2001, le projet a reçu le prix d'excellence architecturale décerné par la municipalité de Budapest $^{15}$. En 2003, il a reçu un prix Europa Nostra ${ }^{16}$, et, en 2005, tous les bâtiments ont été protégés en tant que monuments historiques ${ }^{17}$.

\section{Réutilisation, aspects culturels}

Le site reconverti était le cadre parfaitement approprié pour l'exposition intitulée «Dreamers of Dreams: Hungarians of Worldwide Significance " (les rêveurs de rêves, figures hongroises d'importance mondiale). Montée dans le cadre des événements destinés à célébrer le millénaire de l'État hongrois, l'exposition cherchait à mettre en valeur les acquis hongrois des siècles passés, notamment dans le domaine de la science et de la technologie, ainsi que dans celui des arts, de la culture et des sports. Suivant les critères établis par des comités de pilotage académiques, traduits dans le décret gouvernemental pour la création de l'exposition, la aleur d'universalité était le critère fondamental de sélection ${ }^{18}$. Ainsi, installée dans le magnifique espace des halles d'usinage et de montage réunies, l'exposition attirait l'attention sur les travaux de 689 personnalités d'exception, en suivant l'évaluation des acquis hongrois dans un 
contexte global. Les inventions et les activités professionnelles des grands ingénieurs de l'usine Ganz étaient particulièrement mises en valeur dans l'exposition, étant donné l'importance historique de l'entreprise sur le plan local et international ${ }^{19}$.

En raison du grand encombrement et de la grande valeur des objets et des artéfacts exposés, en raison aussi des techniques innovantes utilisées dans la présentation muséographique (fig. 13), l'exposition a connu un succès retentissant, avec plus d'un demi-million de visiteurs en dix mois ${ }^{20}$. En Hongrie, aucune exposition avant, ni après, n'a connu une telle affluence. La mise en valeur des impacts globaux de la créativité hongroise, et le succès auprès d'une population massive ont fait de "Dreamers of Dreams » une étape importante dans la vie culturelle du pays ${ }^{21}$. En dépit de ce grand succès, toutefois, et malgré l'ambition de conserver sur le site un certain nombre des objets rassemblés pour l'exposition, celle-ci a fermé ses portes au bout d'un an en raison de difficultés, y compris financières.

Figure 13

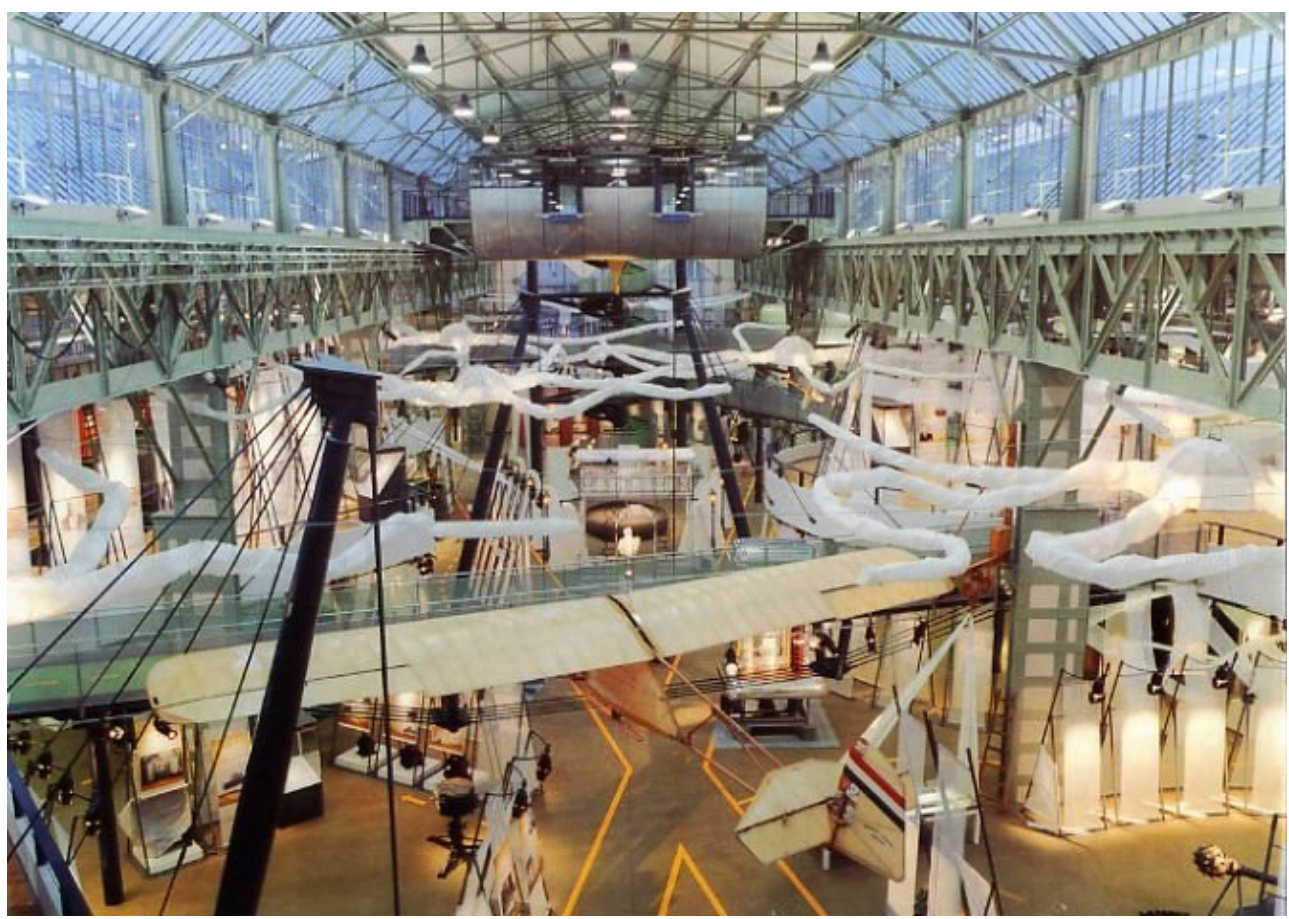

Détail de l'exposition intitulée Dreamers of Dreams : Hungarians of Worldwide Significance.

Phot. Häider, Andrea. @ Magyar Építőmúvészet.

Néanmoins, l'association de la science et de la culture est restée au centre du projet de reconversion, toujours combinée avec un respect des valeurs historiques du site. Ainsi, un "palais des Miracles », un musée scientifique interactif conçu pour expliquer des principes scientifiques aux enfants de manière simple et ludique, a été installé dans la grande halle d'usinage. D'autres initiatives culturelles assez diversifiées ont été lancées dans d'autres bâtiments. L'ancien atelier de réparations, rebaptisé Fogadó (qui signifie « auberge » en hongrois), avec l'ancienne usine à transformateurs, rebaptisée Teátrum, accueillent des performances théâtrales, des concerts et des ballets et est aussi disponible pour des colloques et des congrès. La halle de montage, dorénavant la halle $\mathrm{B}$, a pu accueillir plusieurs expositions temporaires, comme par exemple le salon national du Livre (fig. 14). Pour la cérémonie d'ouverture de la présidence hongroise de 
l'Union européenne, en 2011, l'ensemble du site a accueilli un programme d'interventions culturelles très spectaculaires, comprenant par exemple des projections vidéo en haute résolution sur les façades des édifices ${ }^{22}$.

Figure 14

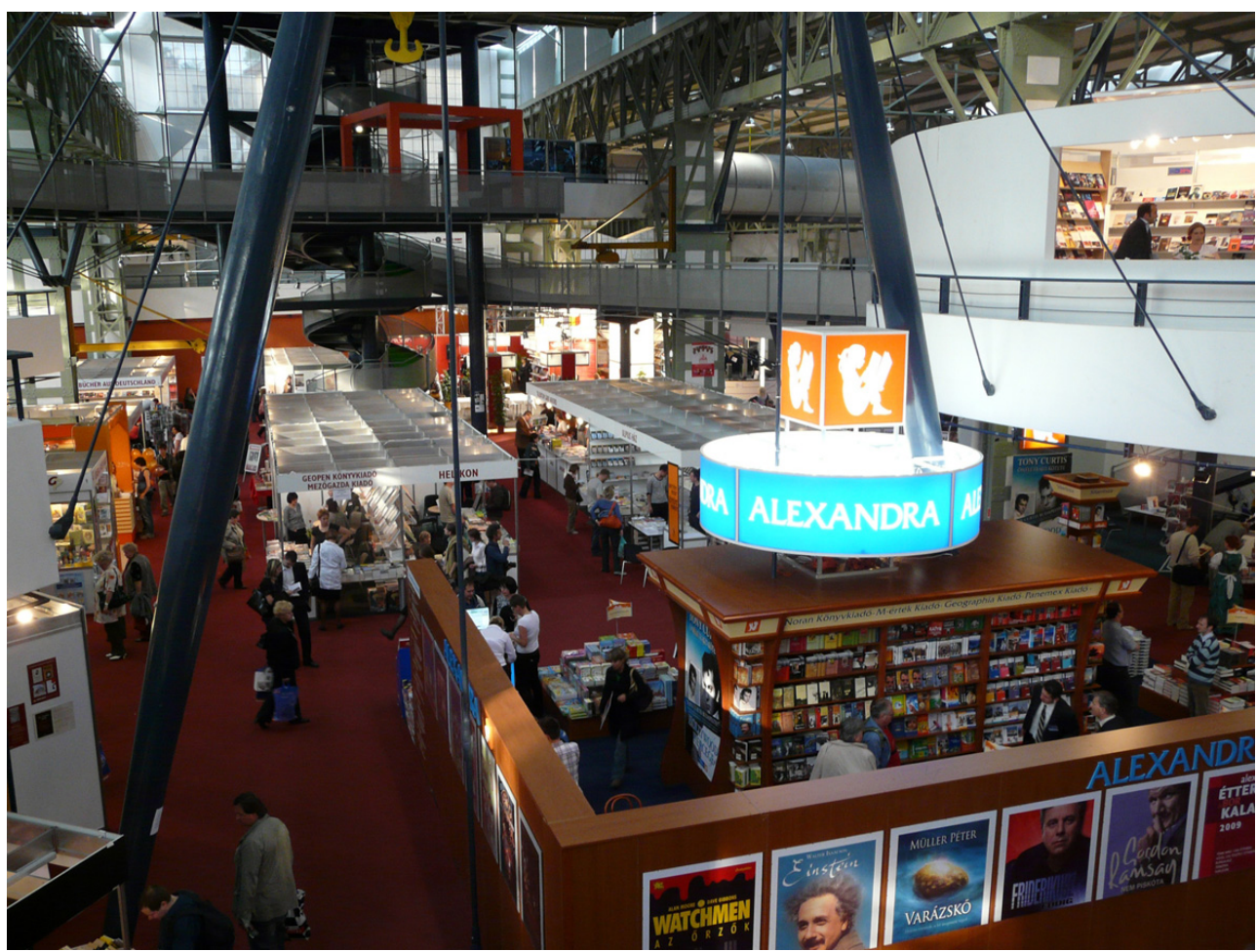

SEIZIÈME SALON INTERNATIONAL DU LIVRE, 23-26 AVRIL 2009, DANS LA HALLE DE MONTAgE.

Phot. Vadaro. (c) Vadaro. CC-BY-SA-3.0-2.5-2.0-1.0 (www.creativecommons.org/licenses/by-sa/3.0), via Wikimedia Commons.

17 En dehors du palais des Miracles, spécialement conçu pour un jeune public, d'autres projets culturels ciblent les enfants, comme par exemple des spectacles de marionnettes ou encore des « concerts chocolat " pour initier les enfants à la musique classique. Ce que les enfants préfèrent, toutefois, est l'aire de jeu Zöld Péter, primée par le ministère du Patrimoine culturel national pour sa conception artistique ${ }^{23}$. Construite avec des sculptures contemporaines en bois, cette aire de jeu offre aux enfants la possibilité de revivre les aventures de Zöld Péter, le jeune héros d'un conte hongrois pour enfants. Ainsi, avec ce large éventail de possibilités culturelles, le Millénaris a trouvé une fonction permanente de complexe culturel moderne, attirant tout spécialement un public familial.

\section{L'environnement : de la dépollution au paysagisme}

18 L'approche du projet de régénération prenait en compte la question du paysage, et pour un site sérieusement contaminé, les concepteurs ont innové dans les méthodes de revitalisation, créant un environnement attractif et plein de sens. Le lac aux contours irréguliers placé au centre du Millenáris est en réalité une solution économique pour remplacer les terres polluées enlevées (fig. 15). Par la suite, les espaces laissés libres autour des bâtiments reconvertis ont été divisés en parcelles distinctes, où une flore 
particulière a réussi à donner à chacune un caractère distinctif. À la place des fleurs et des buissons que l'on voit habituellement dans les jardins, on a retenu des plantes caractéristiques de l'agriculture hongroise, comme le blé ou la vigne, et des essences comme l'érable ou le pommier sauvage. Ces plantes et arbres sont rassemblés par groupes, même au milieu du lac (fig. 16), tandis que des pelouses ont été créées partout, y compris sur les bancs publics ${ }^{24}$.

Figure 15

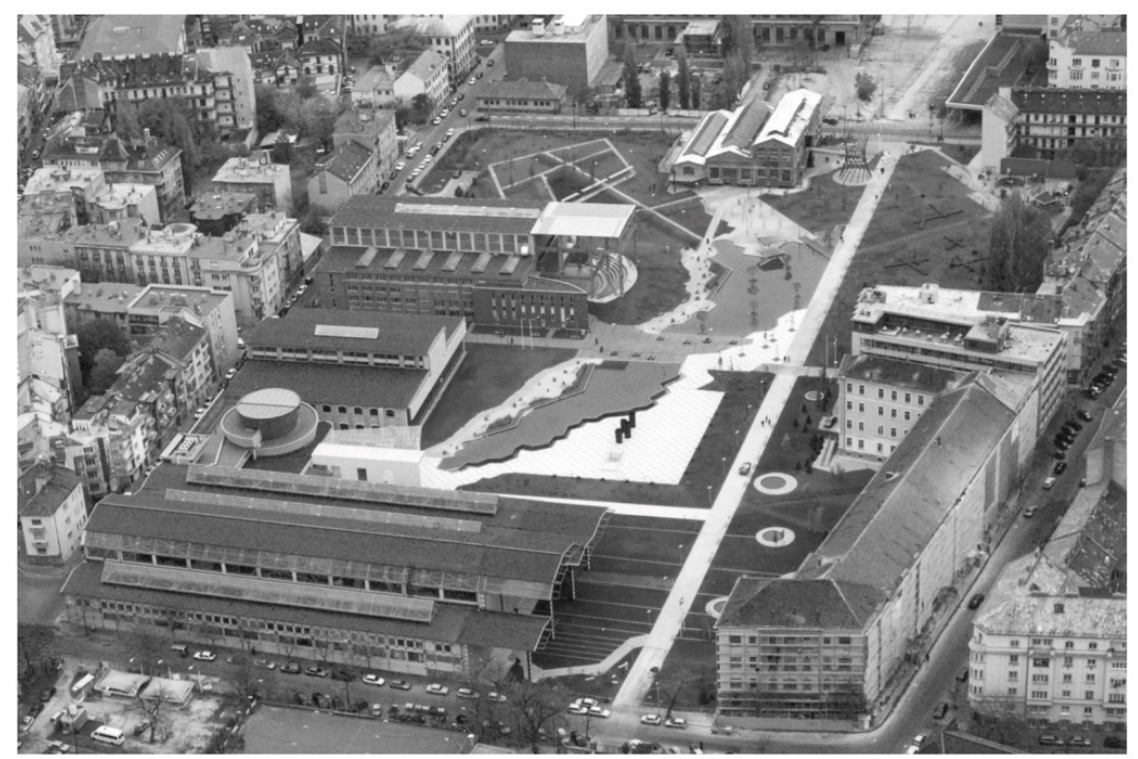

Vue aérienne du site du Millenáris ; le lac au centre remplit le vide laissé par l'enlèvement des terres polluées. RADVÁNYI, György. «The future of industrial buildings and industrial plants : fatal or promising?» Dans NÉMETH, Györgyi (ed.). Growth, Decline, and Recovery: Heavy Industrial Regions in Transition. Budapest : Institute of History of the Hungarian Academy of Sciences, Miskolc : University of Miskolc, 2007, p. 304

REPRO. NÉMETH, GYöRgYI. (C) GYöRgYI NÉMETH. 


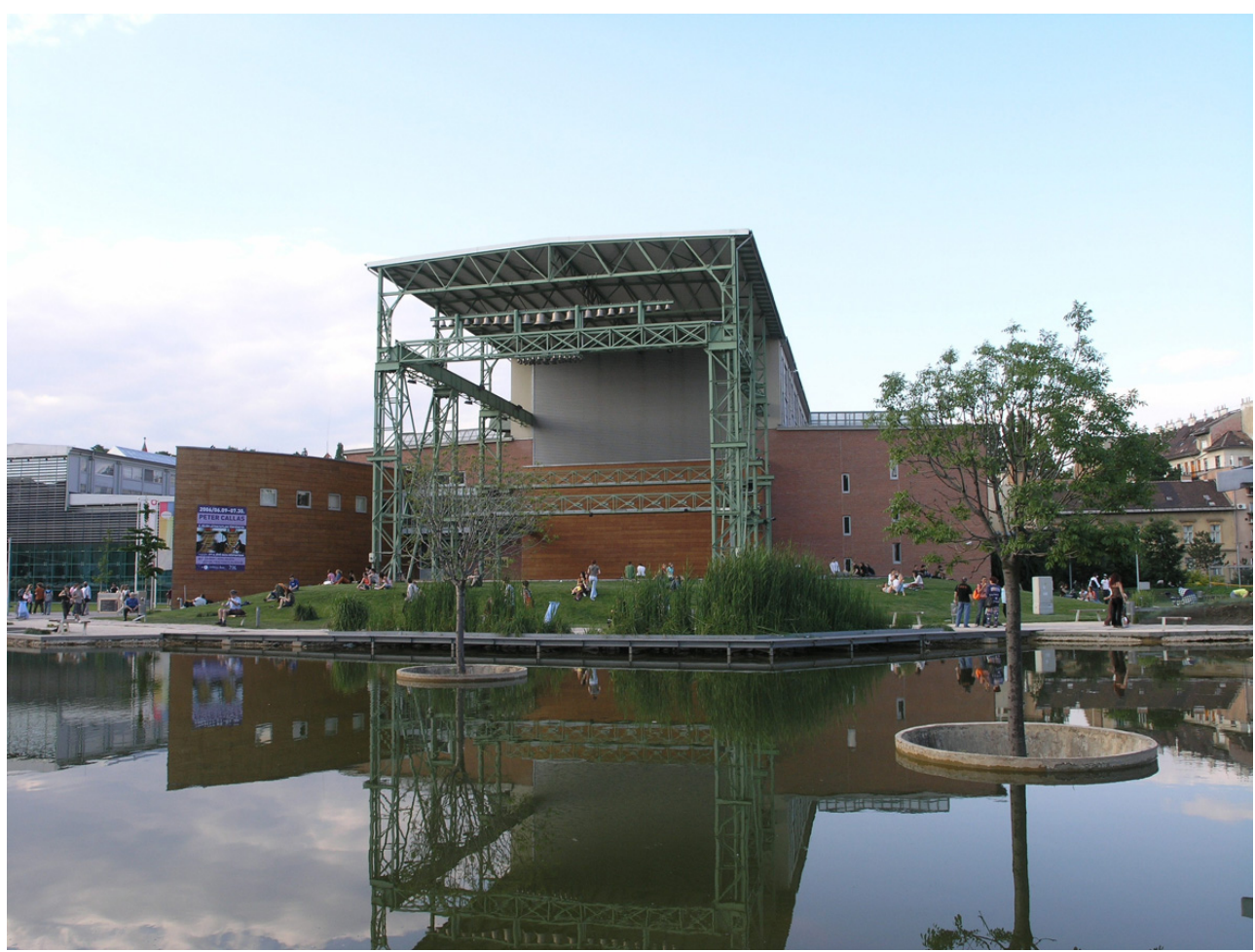

La conception paysagère du site.

Phot. Németh, Györgyi. (c) Györgyi Németh.

Grâce à ces caractéristiques, le parc donne une cohérence d'ensemble au site autour du lac et autour des bâtiments, et propose un message clairement énoncé, en concordance avec les ambitions du projet de régénération. En reconnaissant et en appréciant les acquis de l'ingéniosité hongroise, les visiteurs qui déambulent à travers le parc peuvent trouver de l'inspiration pour devenir eux-mêmes des inventeurs ${ }^{25}$. En même temps, ces visiteurs pourront développer une conscience plus aiguë de leur environnement. Renforcée par des programmes liés à l'écologie comme les ateliers sur les maisons autonomes organisés dans les halles ${ }^{26}$, ou encore par les projets de jardins communautaires dans quelques recoins du parc, cette initiative a séduit de nombreux participants.

\section{Le quartier : créer du lien}

La régénération du site de l'usine Ganz a eu des retombées très positives pour les habitants du quartier. À la place d'une usine en déshérence, fortement polluée, ils trouvent un espace public agréable, doté d'équipements excellents dans un paysage de verdure unique. Les citoyens qui habitent près du site peuvent bénéficier des programmes culturels ou profiter plus simplement du nouveau parc, devenu un véritable parc public où les habitants peuvent se retrouver pour discuter de leurs problèmes personnels ou de ceux de la communauté.

En même temps, le nombre considérable de visiteurs témoigne de l'attractivité du site pour un public plus large. Il y a un consensus national sur la réussite de ce programme de régénération ${ }^{27}$. Une fierté collective vis-à-vis des acquis du Millenáris rassemble les 
membres de la communauté nationale, par ailleurs divisés par leurs points de vue antagonistes. De plus, les visiteurs étrangers sont très attirés par le site, grâce à ses ressources très diversifiées et son atmosphère particulière.

\section{Architecture récente et conservation future}

L'appréciation du public, soutenue par les mesures de reconnaissance de l'office national pour le patrimoine culturel, a été une force majeure dans la préservation de l'intégrité du site, en dépit de quelques opérations de construction neuve ${ }^{28}$. Un projet très ambitieux pour le développement d'un ensemble de logements et de locaux tertiaires, qui représentait une menace pour les bâtiments historiques reconvertis, a été revu à la baisse et, en fin de compte, il n'y a que trois édifices neufs, abritant des locaux tertiaires de grand standing, qui ne portent pas atteinte aux valeurs historiques du site. En effet, parmi ces trois bâtiments neufs, le premier masque de manière flatteuse la façade postérieure d'une maison du voisinage, le deuxième prend la place d'un bâtiment de l'usine sans valeur particulière ${ }^{29}$, tandis que le troisième est le bâtiment de bureaux de 1897 entièrement modernisés ${ }^{30}$.

Des propositions pour la réutilisation des ateliers datant des années 1960, actuellement situés en dehors du périmètre du Millenáris, ont pour ambition d'accroître encore la valeur du site, conformément aux intentions initiales. Dans la halle d'assemblage par exemple, actuellement la halle $\mathrm{M}^{31}$, un musée des sports sera peut-être installé, abritant des collections et offrant une histoire des victoires hongroises dans le domaine des sports $^{32}$.

\section{Impact dans le pays}

Inspiré par les multiples valeurs culturelles, environnementales et sociales du Millenáris , un projet similaire de régénération a récemment été achevé à Pécs, une ville importante du sud de la Hongrie. Le quartier culturel de Zsolnay englobe le site d'une usine de céramique architecturale créée dans la deuxième moitié du $\mathrm{xIX}^{\mathrm{e}}$ siècle par Vilmos Zsolnay, inventeur d'une nouvelle faïence et d'une technique multicolore en éosine, récompensées aux Expositions universelles de Paris, et d'un nouveau matériau de construction, la pyrogranite, utilisé dans l'Art nouveau hongrois. Dans des bâtiments du site, conservés et réhabilités, et comprenant des bâtiments de production aussi bien que la villa patronale, une grande variété d'activités culturelles a été mise en place, suivant l'exemple du Millenáris. Des expositions sur l'histoire de la famille Zsolnay et sur les produits de ses usines figurent parmi ces initiatives, mais il y a aussi des démonstrations scientifiques ludiques et des spectacles de marionnettes pour petits et grands ${ }^{33}$.

Malheureusement, ce projet n'était pas tout à fait achevé pour accueillir les programmes prévus dans le cadre de "Pécs, capitale culturelle de l'Europe » (en même temps qu'Essen et Istanbul) en $2010^{34}$. Mais le site reconverti représente néanmoins une contribution importante à la vie culturelle de la ville, tout en offrant des espaces prestigieux pour la communauté locale, dans un environnement renouvelé. Lorsque l'on considère la diversité des bénéfices qui découlent de ces projets culturels de reconversion du patrimoine industriel, initiée au Millenáris et reprise dans le quartier 
culturel de Zsolnay à Pécs, il ne fait pas de doute que d'autres sites industriels à l'abandon devraient être régénérés de la même manière à travers tout le pays.

\section{NOTES}

1. - BERLÁSZ, Jenő. «Ábrahám Ganz (1814-1867), Bahnbrecher der ungarischen Schwerindustrie ", tiré à part de Zürcher Taschenbuch, 1967, p. 110-125.

2. - «Un discours sur André Mechwart». Revue de Hongrie, 1908, vol.1, p. 103-104 ; PAULINYI, Akos. «Industrieförderung und Techniktransfer aus dem Deutschen Reich nach Ungarn zwischen 1880 und 1914 ». Dans FISCHER, Holger et SZABADVÁRY, Ferenc (dir.). Technologietransfer und Wissenschafstaustausch zwischen Ungarn und Deutschland. Aspekte der historischen Beziehungen in Naturwissenschaft und Technik, Südosteuropäische Arbeiten 94. München: Oldenbourg, 1995, p. 183-184; « Mechwart, Andreas ». Dans JÄGER, Kurt et HEILBRONNER, Friedrich (dir). Lexikon der Elektrotechniker. Berlin/Offenbach : VDE Verlag, 2010, p. 281.

3. - ASZTALOS, Péter. Product development of the century-old Ganz Electric Works, 1878-1978. Budapest : Ganz Villamossági Müvek [1981], p. 5-9, 17-19.

4. - Kandó conference 2006: in memoriam Kandó Kálmán : Budapest Tech Kandó Kálmán Faculty of Electrical Engineering : 12-13 January $2006: 23$, scientific session, abstracts. [Budapest] : [BMF KKVK], [2006] ; « Kandó Kálmán ». Dans JÄGER, Kurt et HEILBRONNER, Friedrich (dir.), op. cit., p. 219.

5. - KANDÓ, Kálmán. « Neue elektrische Güterszugslokomotive der italienischen Staatsbahnen ». Zeitschrift des Vereins deutscher Ingenieure, 1909, vol. 53, p. 1249-1253, 1320-1325 ; ASZTALOS, Péter, op. cit., p. 44-47.

6. - Ibid., p. 86 ; SZEKERES, Jószsef et TÓTH, Árpád. A Klement Gottwald (Ganz) Villamossági Gyár története [L'histoire de l'usine de construction électrique Klement Gottwald (Ganz)]. Budapest : Közgazdasági és Jogi Kiadó, 1962, p. 90-92.

7. - Ibid., p. 116-112, 220-227, 263-266, 280, 305-306. Concernant la figure 2: Javaslat müemléki értékek védetté nyilvánitására. Az egykori Ganz-gyár épületegyüttese [Proposition de protection de monuments de valeur, site de l'ancienne usine de construction électrique Ganz] Müemléki törzsszám [Numéro du monument]: 16001. Office national du patrimoine culturel, Nyilvántartási Iroda [Département d'enregistrement]. Budapest, 2004. Appendix 4.

8. - BAZSÓ, Gábor. Budapest, II. Lövőház u. 39 Ganz Villamossági Gyár. B és D üzemcsarnok (Nagyszerelde, Nagyforgácsoló) [L'usine de construction électrique Ganz. Halles B et D (halles de montage et d'usinage)]. Tudományos dokumentáció [archives documentaires]. Office national du patrimoine culturel, Tervtár [Dépôt documentaire] 42227. Budapest, 2000, p. 19 ; CG Electric Systems Hungary, http://www.cgglobal.com/others/joint-ventures/cg-Electric-Hungary-NV.html [consulté le 10/04/2012].

9. - LOCSMÁNDI, Gábor. « Séta a parkban. A walk round the park ». Új Magyar Építőművészet, 2002, $\mathrm{n}^{\circ}$ 1, p. 21 ; LAMPERT, Rózsa, « The Ganz Park - Budapest ». Dans KIRIZSÁN, Imola et HLAVATHY, Izabella (dir.). A realistic approach to built heritage conservation, Baia Mare, 25-28 May 2005, Conference series on theoretical and practical issues of built heritage conservation. Cluj : Utilitas, 2005, p. 148-149. Concernant la figure 3 : Javaslat müemléki értékek védetté nyilvánitására. Az egykori Ganzgyár épületegyüttese [Proposition de protection de monuments de valeur, site de l'ancienne usine de construction électrique Ganz]. Müemléki törzsszám [Numéro du monument]: 16001. Office 
national du patrimoine culturel, Nyilvántartási Iroda [Département d'enregistrement]. Budapest, 2004. Appendix 7.

10. - BAZSÓ, Gábor, op. cit., p. 20-22.

11. - RÉPAY, András. " Millenium Exhibition and Program Center, $2^{\text {nd }}$ District, Budapest ». Dans KIRIZSÁN, Imola et HLAVATHY, Izabella (dir.). Op. cit., p. 160-170 ; Javaslat müemléki értékek védetté nyilvánítására. Az egykori Ganz-gyár épületegyüttese [Proposition de protection pour monuments de valeur. Le site de l'ancienne usine Ganz]. Müemléki törzsszám [Numéro du monument]: 16001, Office national du patrimoine culturel, Nyilvántartási Iroda [Département d'enregistrement], Budapest, 2004, p. 11-17.

12. - SOMOGYI, Krisztina. « Give me space ». Octogon, 2001, $\mathrm{n}^{\circ} 4$, p. 30.

13. - BOJTI, András. Ganz pipes or thoughts about the connection between contemporary public-place plastic art and architecture. http://epiteszforum.hu/node/10157 [consulté le 10/04/2012].

14. - RÉPAY, András. Art. cit., p. 172.

15. - Budapest Építészeti Nívódíja 2001 [Prix de Budapest pour l'excellence architecturale], http://epiteszforum.hu/node/4226 [consulté le 12/05/2012].

16. - BOJÁR, Iván András (ed.). Közben. In the meantime. A magyar épitészet 15 éve a rendszerváltástól az EU-ba lépésig, 1989-2004. 15 years of architecture from the change of the political system to the EU accession 1989-2004. Octogon könyvek 4 [Budapest] : [Mücsarnok], [2004], p. 90, 100.

17. - «A nemzeti kulturális örökség miniszterének 25/2005. (IX. 16). NKÖM rendelete [Nº 25/2005. (IX.16) NKÖM ordre du Ministre du patrimoine culturel national] ». Magyar Közlöny, $2005, \mathrm{n}^{\circ} 124$, p. 6641.

18. - «A Kormány 1130/1999. (XII. 21.) Kormányhatározata [No. 1130/1999. (XII. 21.) Décret gouvernemental] ». Magyar Közlöny, 1999, n 118, p. 7919.

19. - ÁRKOS, Iván. «Az,Álmok álmodói - világraszóló magyarok” a Millenáris 2002. . kiállítás elektronikus képei. The "Dreamers of Dreams -World-Famous Hungarians". The electronic pictures in the Millenary Exhibition Hall". Tudományos és Müszaki Tájékoztatás, 2002, nº 8. http:// tmt.omikk.bme.hu/show_news.html?id=749\&issue_id=43, http://tmt.omikk.bme.hu/show_newsen.html?id=731\&issue_id=43 [consulté le 12/05/2012].

20. - "CD-ROM-on az Álmok álmodói [Les rêveurs des rêves - CD-ROM] ». Filmkultúra, 12. 23 : http://www.filmkultura.hu/regi/2003/news/public.hu.html [consulté le 12/05/2012].

21. - WESSELÉNYI-GARAY, Andor. «Installált titok. Álmok Álmodói - Világraszóló Magyarok. Installed Secrets. Dreamers of Dreams - Hungarians of Worldwide interest. " Új Magyar Épitőmüvészet, 2002, nº 1, p. 27 ; GYÖRGY, Péter. «Világraszóló magyarok - világkiállítás a mai magyaroknak [World famous Hungarians - World Fair for Modern-day Hungarians]». 2000, 2002, $\mathrm{n}^{\circ}$ 3, p. 70-76.

22. - New year's eve in the name of cultural diversity. http://www.eu2011.hu/news/new-yearseve-name-cultural-diversity [consulté le 12/05/2012].

23. - Hungarian design award, 2000-2011. [Budapest] : Hungarian Intellectual Property Office, 2012, p. 7.

24. - SOMOGYI, Krisztina. Art. cit., p. 28 ; KOVÁCS, Árpád, LENDVAI, Gábor, MUSZBEK, Johanna, POZSÁR, Péter, TIHANYI, Dominika. « Új közpark a budai belváros szívében - a Millenáris park [Nouveau parc public au cœur de la ville de Buda, le parc Millenáris]». Tájépítészet, 2001, n² 2.

25. - RÉPAY, András. Art. cit., p. 171-173.

26. - Autonóm Ház a Millenáris Parkban [Maison autonome dans le parc Millenáris], http:// epiteszforum.hu/node/14446 [consulté le 12/05/2012].

27. - Voir, par exemple, PATONAI, Dénes. "Millenáris (köz)park. Millenary (Public) Park». Új Magyar Épitőmüvészet, 2002, nº 1, p. 23 ; LAMPERT, Rózsa. "The Ganz Park - Budapest ». Dans KIRIZSÁN, Imola et HLAVATHY, Izabella (dir.), op. cit., p. 152 ; BALÁZS, Attila. Moszkva tré. http:// epiteszforum.hu/node/9610 [consulté le 12/05/2012]. 
28. - SOMLYÓDY, Nóra. Millenáris/Ganz II : mutatják nekünk a jövőt [Millenáris/Ganz II, l'avenir nous est montré] : http://epiteszforum.hu/node/574 [consulté le 12/05/2012].

29. - Millenáris irodaházak [Bâtiment de bureaux à Millenáris]: http://epiteszforum.hu/node/ 13804 [consulté le 12/05/2012].

30. - Millenáris irodaházak - a régi Ganz törzsépület átalakitása [Bâtiment de bureaux à Millenáris, reconstruction de l'ancien bâtiment de Ganz] : http://epiteszforum.hu/node/12156 [consulté le 12/05/2012]. 31. - Voir la figure 3.

32. - ZSUFFA, Zsolt. Ház a magyar sportért - Sportmúzeum, Budapest - Museum of Sports, Budapest : http://epiteszforum.hu/node/19142 [consulté le 12/05/2012].

33. - Zsolnay Cultural Quarter: http://www.zskn.hu/index.php?nyelv=english [consulté le 18/09/2012].

34. - LEVAI, Márta. «Pécs ». Dans Ex-Post evaluation of 2010 European Capitals of Culture. Final report for the European Commission Directorate General for Education and Culture. Birmingham : Ecorys, 2011, p. 44-65.

\section{RÉSUMÉS}

Le Millenáris, un centre d'exposition et de programmes culturels, a été créé à Budapest afin d'accueillir une manifestation qui célébrait le millénaire de l'État hongrois dans le bassin des Carpates. Cette exposition se concentrait sur les grandes réalisations hongroises des siècles passés, surtout dans les domaines scientifiques et techniques. L'exposition a ouvert ses portes en 2001 dans un ensemble de bâtiments industriels du site de l'ancienne usine de construction électrique Ganz. C'est le premier exemple en Hongrie d'un projet de régénération urbaine qui conserve l'ensemble d'un grand complexe industriel. Il a des retombées positives considérables pour le public local et sert de modèle pour d'autres projets similaires à travers tout le pays.

The Millenáris, the Millenium Exhibition and Cultural Programme Centre was created in Budapest to accommodate a splendid exhibition celebrating the thousandth anniversary of the establishment of the Hungarian state in the Carpathian basin. Focusing on major Hungarian achievements over the past centuries, primarily in the field of science and technology, the exhibition was opened in 2001 in a group of re-used buildings situated on the site of the former Ganz Electric Works. This regeneration project, the first in Hungary aiming at the preservation of an entire industrial complex, has given rise to extraordinary public benefits and has set an example for subsequent reconversion projects throughout the country. 
INDEX

Keywords : Ganz Electric Work, Budapest, Millenáris, Millennium Exhibition and Cultural Programme Centre, Zsolnay cultural quarter at Pécs, Hungary, industrial architecture, industrial heritage, safekeeping, preservation, protection, conversion, valorization, territorial planning, local development

Mots-clés : Usine de construction électrique Ganz, Budapest, Millenáris, Centre d'exposition et de programmes culturels, millénaire de Budapest, Zsolnay quartier culturel à Pécs, Hongrie, architecture industrielle, patrimoine industriel, sauvegarde, préservation, protection, reconversion, valorisation, aménagement du territoire, développement local

\section{AUTEUR}

\section{GYÖRGYI NÉMETH}

Professeur d'université, université de Miskolc, Institut d'histoire, Hongrie gyorgyi_nemeth@yahoo.co.uk bolverus@uni-miskolc.hu 